\title{
Optimum Design of Assembled Cavity Dies for Precision Forging Process
}

\author{
Jun-song Jin $^{1}$ and Xin-yun Wang ${ }^{1, *}$ \\ ${ }^{1}$ State Key Laboratory of Materials Processing and Die \& Mould Technology, Huazhong University of Science and Technology, 1037 \\ Luoyu Road, Wuhan 430074, China
}

\begin{abstract}
For a given three-layer assembled die of cold precision forging gear, the optimum design was implemented based on the elastic solution of the thick-wall cylinder under the admissible tensile stress. A non-uniform interference fit structure was employed, and the minimum tangential tensile stress in the cavity was defined as the objective function. The inner radius $r_{2}$ and outer radius $r_{3}$ of the inner shrink ring, and the interference fit magnitude of matching faces between different layers were defined as variables of the objective function. These variables were optimized with MATLAB software package. The optimized results were verified with elastic-plastic finite element analysis (FEA). Then, forging experiments were conducted according to the calculated data with MATLAB and FEA results. Compared to conventional design methods, the optimized die structure with non-uniform interference fit is effective in prolonging the service life of gear dies more than ten times.
\end{abstract}

\section{Introduction}

Pre-stressing a forging die by shrinking a ring over the outside is a common method to improve the service life of dies and is frequently used in industry. However, the residual compressive and circumferential stresses are introduced into the die during pre-stressing. These residual stresses can significantly reduce the magnitude of circumferential tensile stresses that are aroused in the metal working. Kutuk et al. studied a cylindrical approach for shrink-fit precision cylinder gear forging dies via finite element analysis (FEA) [1]. Fu and Shang analysed the stress of bevel gear forging dies and optimized by the boundary-element method [2]. Song and Im studied the closed-die forging of bevel gears process by FEA. The outer radius of the shrink ring was set to be three times over the maximum radius of the gear according to empirical equations [3]. Zhang designed a double-layer die for cold and warm bevel gear forging experiments [4]. All of the dies used in these studies were designed as one shrink ring. However, pre-stressing of double-layer assembled die is insufficient due to the stress concentration on some occasions, so a three-layer assembled die is required.

The optimum design of three-layer assembled backward and/or forward extrusion dies was studied [6-8]. No tensile stress or minimum tensile stress was defined as the target functions. Die sets with uniform magnitudes of interference fit were designed, and infinite length thick-wall cylinder with uniform inner pressure was assumed in the analysis. The assumption was acceptable according to the experimental results due to the uniform cross-section of inner cavity die along die symmetrical axis.

A typical characteristic of cavity die of bevel gear is that the cross-section along the die symmetrical axis is not uniform. The upper section is a cavity used to pattern bevel gear, and the lower section, named as the thick bottom, with a hole is used to press the blank and eject the forged gear. All of the mentioned papers designed this type of thick bottom dies with a double-layer structure, and the upper section and bottom section have the same magnitude of interference fit [2-4]. Most of the compression effect induced by this uniform interference fit will be borne by the lower section since the lower section has stiffness higher than that of the upper section. The effect of shrink ring will be lowered, and the prestress will be insufficient at the upper section.

For a conventional structure that has the uniform interference fit, cracking may occur at the corner of cavity dies early because of insufficient pre-stress. There are two possible ways to solve this problem. One is to increase the radius at the corner to reduce stress concentration, but this method contributes little to the production because the dimensional change of a precise workpiece is unallowable. The second way is to improve the pre-stress by increasing the magnitude of an interference fit. However, it is limited by the allowable stress of die materials. Further more, a greater magnitude of interference fit will lead to difficult assembly.

The present paper proposed a three-layer assembled die structure with a non-uniform interference fit to improve the effect of shrink ring, and extend the life of dies. As a contrast, a conventional three-layer assembled die with uniform interference fit was analysed (see Fig. 1). The proposed structure with non-uniform interference fit is shown in Fig. 2, and the value of interference fit between the upper section and the inner ring is bigger than that between the lower section and the inner ring, which are marked with circles and crosses, respectively. Parameters of assembled dies were optimized and then verified with FEA. Finally, experiments were conducted in a gear factory according to the analysed results. 


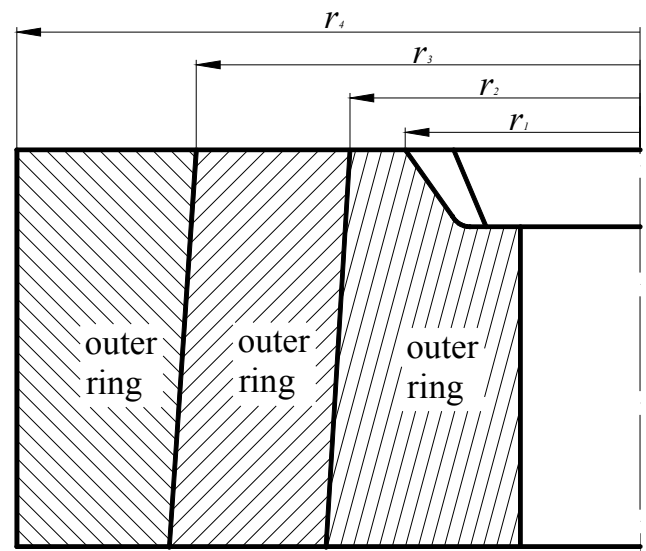

Figure 1. Conventional design of three-layer assembled gear cavity dies.

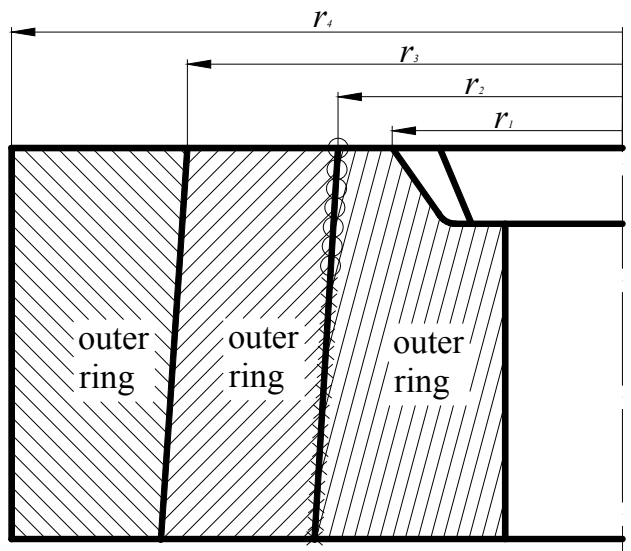

Figure 2. Bevel gear die with a non-uniform interference fit.

\section{Elastic solution model of assembled thick-wall cylinder}

For assembled cold forming dies, the failure of shrink rings is usually aroused by the tangential cracks caused by tensile stress. Since nearly no plastic deformation occurs because of high hardness, the die can be considered as elastic model. When the two shrink rings reach the admissible tensile stress, the maximum compression pre-stress on the die can be obtained.

\subsection{Elastic solutions for single-layer thick-wall cylinder}

Fig. 3 shows a single-layer thick-wall cylinder with inner pressure $p_{i}$ and outer pressure $p_{o}$, the distribution of tangential stress $\sigma_{\theta}$ and radial stress $\sigma_{r}$ can be expressed as:

$$
\begin{gathered}
\sigma_{r}=\frac{r_{i}^{2} r_{o}^{2}\left(p_{o}-p_{i}\right)}{r_{o}^{2}-r_{i}^{2}} \frac{1}{r^{2}}+\frac{p_{i} r_{i}^{2}-p_{o} r_{o}^{2}}{r_{o}^{2}-r_{i}^{2}} \\
\sigma_{\theta}=-\frac{r_{i}^{2} r_{o}^{2}\left(p_{o}-p_{i}\right)}{r_{o}^{2}-r_{i}^{2}} \frac{1}{r^{2}}+\frac{p_{i} r_{i}^{2}-p_{o} r_{o}^{2}}{r_{o}^{2}-r_{i}^{2}}
\end{gathered}
$$

where $r_{i}$ and $r_{o}$ are the inner radius and outer radius, respectively, $r$ varies between $r_{i}$ and $r_{o}$.

\subsection{Stress analysis for three-layer die}

Fig. 4 shows the parameters and pressures in a three-layer assembled die between each layer. According to Equation (2), the tangential stress $\sigma_{\theta 3}$ at radius $r_{3}$ of the outer ring can be expressed as:

$$
\sigma_{\theta 3}=\frac{\left(r_{4}^{2}+r_{3}^{2}\right) p_{3}}{r_{4}^{2}-r_{3}^{2}}
$$

then

$$
p_{3}=\frac{r_{4}^{2}-r_{3}^{2}}{\left(r_{4}^{2}+r_{3}^{2}\right)} \sigma_{\theta 3}
$$

where $p_{3}$ is the interface pressure between the inner ring and outer ring, $r_{3}$ is the interface radius between the inner ring and outer ring and $r_{4}$ is the outer radius of the outer ring. Meanwhile, the tangential stress of the inner shrink ring can be expressed as:

$$
\sigma_{\theta 2}=\frac{p_{2}\left(r_{2}^{2}+r_{3}^{2}\right)-2 p_{3} r_{3}^{2}}{r_{3}^{2}-r_{2}^{2}}
$$

then

$$
p_{2}=\frac{\sigma_{\theta 2}\left(r_{3}^{2}-r_{2}^{2}\right)+2 p_{3} r_{3}^{2}}{r_{2}^{2}+r_{3}^{2}}
$$

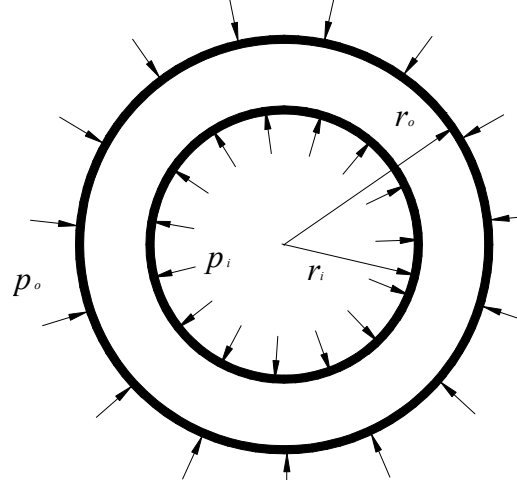

Figure 3. A single-layer thick-wall cylinder with inner pressure $p_{i}$ and outer pressure $p_{o}$

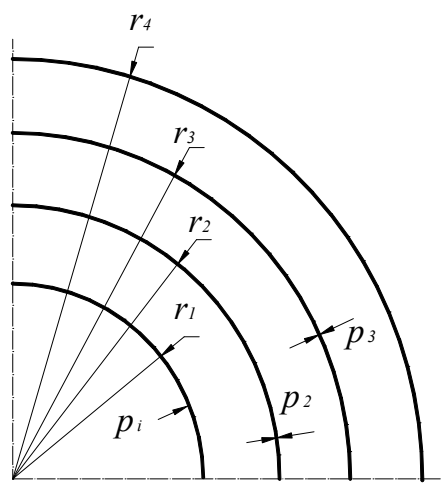

Figure 4. Parameters for three-layer assembled cavity die.

where $\sigma_{\theta 2}$ is the admissible tensile stress for the inner ring, $p_{2}$ is the interface pressure between the inner ring and 
cavity die, and $r_{2}$ is the interface radius between the cavity die and inner ring. The tangential stress $\sigma_{\theta=r l}$ at the equivalent inner face of the cavity die can be expressed with inner pressure $p_{i}$ and outer pressure $p_{2}$ as:

$$
\sigma_{\theta=r_{1}}=\frac{-2 p_{2} r_{2}^{2}+p_{i}\left(r_{2}^{2}+r_{1}^{2}\right)}{r_{2}^{2}-r_{1}^{2}}
$$

\section{Interference magnitude calculation}

The magnitudes of interference fit of a three-layer assembled die are derived from a simpler double layer shrink ring. Fig. 5 shows an assembled double-layer thick-wall cylinder with no inner pressure and outer pressure, the assembled pressure $p$ on interface can be expressed as [9]:

$p=\frac{E \delta}{r_{m}} \frac{\left(r_{m}{ }^{2}-r_{i 1}{ }^{2}\right)\left(r_{o 1}{ }^{2}-r_{m}{ }^{2}\right)}{2 r_{m}{ }^{2}\left(r_{o 1}{ }^{2}-{r_{i 1}}^{2}\right)}$

then

$\delta=\frac{2 r_{m}^{3}\left(r_{o 1}^{2}-r_{i 1}^{2}\right) p}{E\left(r_{m}{ }^{2}-r_{i 1}^{2}\right)\left(r_{o 1}{ }^{2}-r_{m}{ }^{2}\right)}$

Where, $\delta$ is the magnitude of an interference fit, $r_{i l}$ is the inner radius of inner cylinder, $r_{o l}$ is the outer radius of the outer cylinder, and $\mathrm{rm}$ is the interface radius between the two assembled cylinders.

The interface pressure aroused by shrinking between the cavity die and inner ring is named as $p_{2}^{\prime}$, while $p_{3}^{\prime}$ is that between the inner ring and outer ring. These two pressures are used to calculate the interference magnitudes of a three-layer assembled die as displayed in Fig. 4.

The radial stress $\sigma_{r=r 3}^{\prime}$ at $r=r_{3}$ led by $p_{2}$ is

$$
\sigma_{r=r_{3}}^{\prime}=\frac{p_{2} r_{2}^{2}}{r_{4}^{2}-r_{2}^{2}}\left(1-\frac{r_{4}^{2}}{r_{3}^{2}}\right)
$$

then

$$
p_{3}^{\prime}=p_{3}+\sigma_{r=r_{3}}^{\prime}
$$

The radial stress $\sigma_{r=r 2}^{\prime}$ at $r=r_{2}$ led by $p_{3}^{\prime}$ is

$$
\sigma_{r=r_{2}}^{\prime}=-\frac{p_{3}^{\prime} r_{3}^{2}}{r_{3}^{2}-r_{1}^{2}}\left(1-\frac{r_{1}^{2}}{r_{2}^{2}}\right)
$$

The radial stress $\sigma_{r=r 2}^{\prime \prime}$ at $r=r_{2} \quad$ led by the inner pressure $p_{i}$ is

$$
\sigma_{r=r_{2}}^{\prime \prime}=\frac{p_{i} r_{1}^{2}}{r_{4}^{2}-r_{1}^{2}}-\frac{r_{1}^{2} r_{4}^{2} p_{i}}{r_{4}^{2}-r_{1}^{2}} \frac{1}{r_{2}^{2}}
$$

then

$$
p_{2}^{\prime}=p_{2}+\sigma_{r=r_{2}}^{\prime}+\sigma_{r=r_{2}}^{\prime \prime}
$$

According to Equation (9), the interference magnitudes at $r=r_{2}$ and $r=r_{3}$ are expressed as:

$$
\delta_{2}=\frac{2 r_{2}^{3}\left(r_{4}^{2}-r_{1}^{2}\right) p_{2}^{\prime}}{E\left(r_{2}^{2}-r_{1}^{2}\right)\left(r_{4}^{2}-r_{2}^{2}\right)}
$$

$$
\delta_{3}=\frac{2 r_{3}^{3}\left(r_{4}^{2}-r_{1}^{2}\right) p_{3}^{\prime}}{E\left(r_{3}^{2}-r_{1}^{2}\right)\left(r_{4}^{2}-r_{3}^{2}\right)}
$$

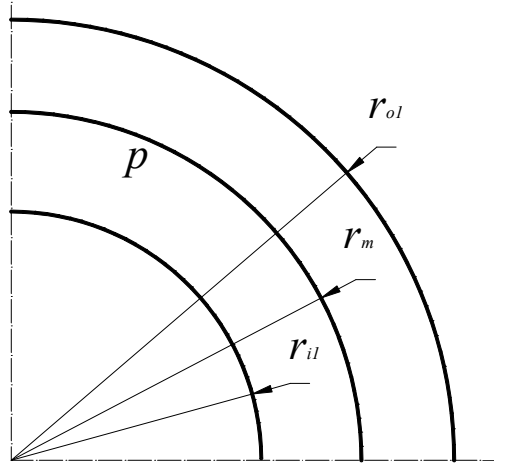

Figure 5. Model for the assembled double-layer thick-wall cylinder.

\section{Parameter optimization procedure}

The equivalent radius of a cavity die is a constant and marked with $r_{1}$, while $r_{2}$ and $r_{3}$ are variables, Equation (7) is defined as the target function and the target is to get the minimum value of $\sigma_{\theta=r l}$. Since Equation (7) is a higher order equation, it is very difficult to give its analytic solution by partial derivative methods, so computer programming method was used and MATLAB software was employed as a programming tool.

Fig. 6 briefly shows the flow diagram of searching algorithm for optimization procedure. The algorithm of the optimization procedure for target value is as follows:

Stage 1. Input the minimum value of design variable $r_{2}$, and initialize design variable $r_{3}$, where $r_{2}<r_{3}<r_{4}$. 
Stage 2. Calculate the value of the objective function (7), if the value reaches the minimum, go to the next stage, otherwise update $r_{3}$ with an increment $\Delta r_{3}$ until $r_{3}=$ $r_{4}$.

Stage 3. If the value reaches the minimum for $r_{2}$, go to the next stage, otherwise update $r_{2}$ with an increment $\Delta r_{2}$ and go to Stage 2. If $r_{2}=r_{4}$, go to next stage.

Stage 4. If $r_{2}=r_{4}$, a single layer die is designed; else if $r_{2}=r_{3} \neq r_{4}$ or $r_{2} \neq r_{3}=r_{4}$, a double layer die is designed, output the target value and the corresponding values of $r_{2}$ and $r_{3}$, and calculating $\delta_{2}$ and $\delta_{3}$ by Equations (8)-(16);

Else, output the target value and the corresponding values $r_{2}$ and $r_{3}$ and calculating $\delta_{2}$ and $\delta_{3}$ by Equations (8)-(16)

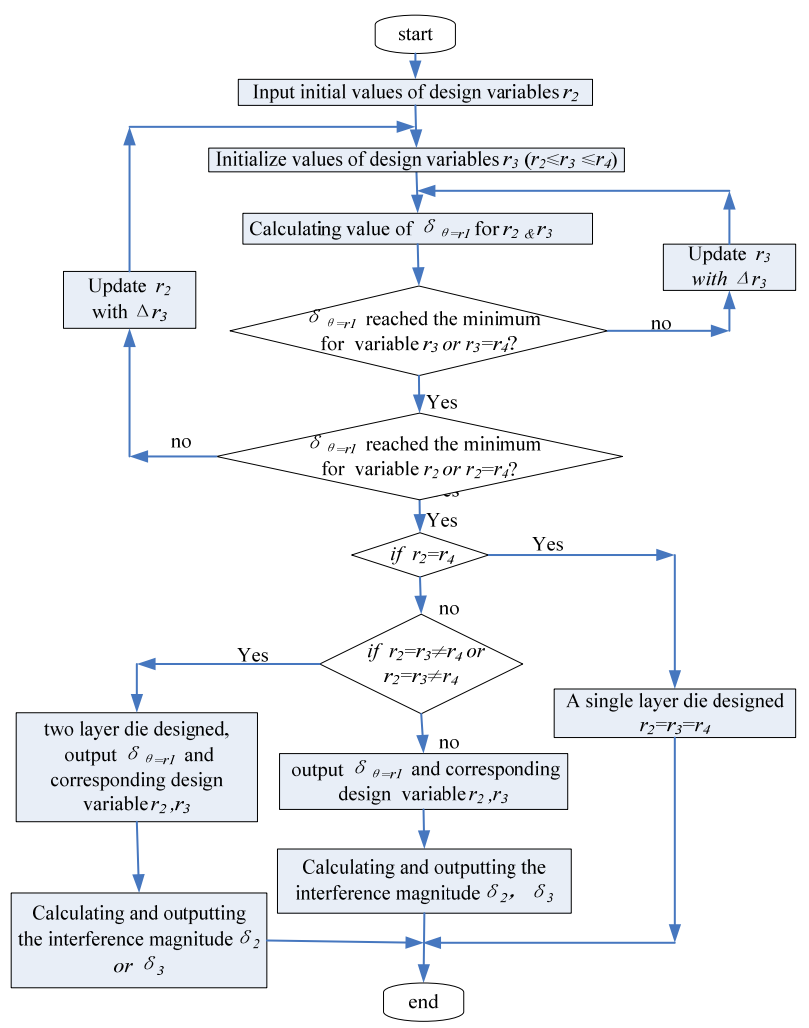

Figure 6. Schematic of the calculation flow in MATLAB.

\section{Optimized parameters and conventionally designed parameters}

The material parameters of assembled dies are shown in Table 1 . The geometry parameters and magnitudes of an interference fit between each layer designed with the conventional method [10] and proposed method are shown in Tables 2 and 3, respectively. The inner pressure $p_{i}$ was $2500 \mathrm{MPa}$.

The increment values of $\Delta r_{2}$ and $\Delta r_{3}$ were set to 0.1 $\mathrm{mm}$. An optimum value was obtained after 353197 steps of iteration.
Table 1. Material parameters for each layer.

\begin{tabular}{|c|c|c|c|}
\hline Name & Material & $\begin{array}{c}\text { Admissible stress } \\
\text { (MPa) }\end{array}$ & $\begin{array}{c}\text { Hardness } \\
\text { (HRC) }\end{array}$ \\
\hline Cavity die & $65 \mathrm{Nb}$ & 2400 & $\geq 60$ \\
\hline Inner ring & $5 \mathrm{CrNiMo}$ & 1200 & $40-45$ \\
\hline Outer ring & $5 \mathrm{CrNiMo}$ & 1200 & $>35$ \\
\hline
\end{tabular}

Table 2. Magnitudes of interference fit.

\begin{tabular}{|c|c|c|}
\hline Method & $\boldsymbol{\delta}_{\mathbf{2}}$ & $\boldsymbol{\delta}_{\mathbf{3}}$ \\
\hline Traditional method & 0.533 & 0.391 \\
\hline Optimized method & 0.465 & 0.412 \\
\hline
\end{tabular}

Table 3. Geometry parameters and corresponding stress.

\begin{tabular}{|c|c|c|c|c|c|}
\hline Method & $\begin{array}{c}\boldsymbol{r}_{1} \\
(\mathbf{m m})\end{array}$ & $\begin{array}{c}\boldsymbol{r}_{2} \\
(\mathbf{m m})\end{array}$ & $\begin{array}{c}\boldsymbol{r}_{3} \\
(\mathbf{m m})\end{array}$ & $\begin{array}{c}\boldsymbol{r}_{4} \\
(\mathbf{m m})\end{array}$ & $\begin{array}{c}\boldsymbol{\sigma}_{\theta=\boldsymbol{r}} \\
(\mathbf{M P a})\end{array}$ \\
\hline $\begin{array}{c}\text { Traditional } \\
\text { methods }\end{array}$ & 30 & 51 & 87 & 300 & 543 \\
\hline $\begin{array}{c}\text { optimized } \\
\text { methods }\end{array}$ & 30 & 43.5 & 81 & 300 & 411 \\
\hline
\end{tabular}

\section{FEA of the dies}

\subsection{FEA model}

To verify the results, FEA was carried on with Ansys soft package. Elastic-plastic dies were considered in simulation, considering the high hardness and small temperature variation. The Young's modules of the cavity die and rings were set to 2.07E5 $\mathrm{MPa}$ and 2.10E5 MPa, respectively. The stress-strain curves of the materials at room temperature were illustrated in Figs. 7 and $8[11$, 12].

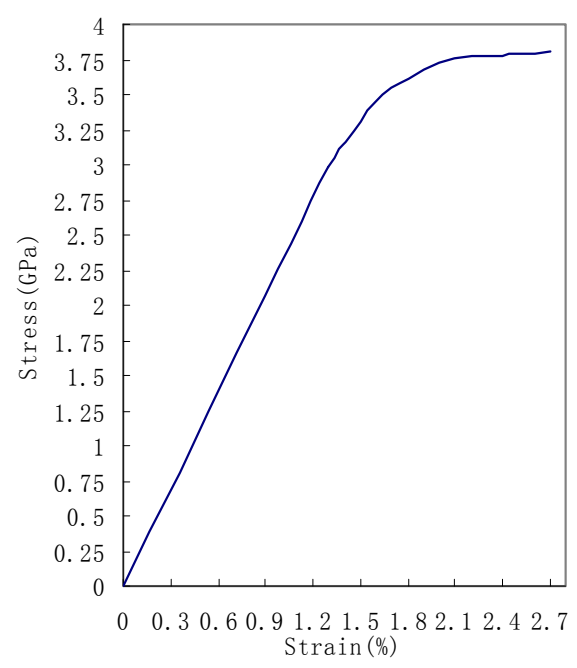

Figure 7. Stress-strain curve of $65 \mathrm{Nb}$. 


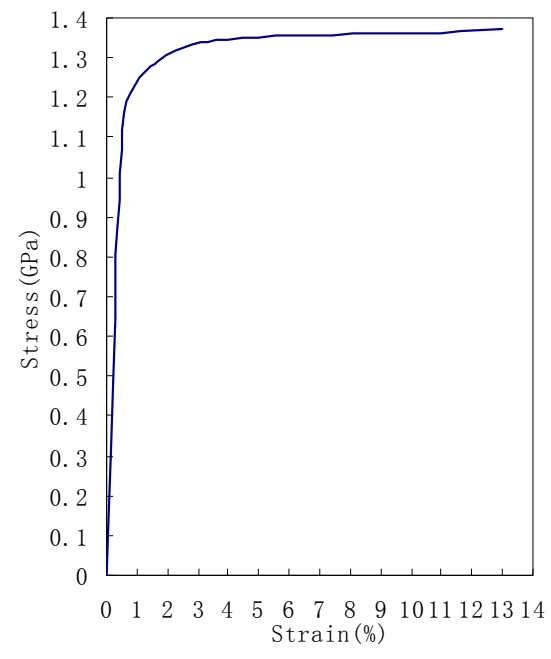

Figure 8. Stress-strain curve of $5 \mathrm{CrNiMo}$.

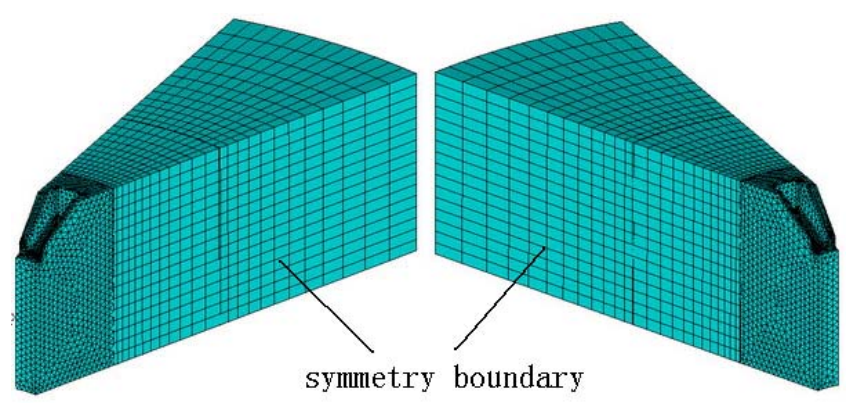

Figure 9. The FEA model.

Three types of die structures were modelled in simulations. The first one was modelled with uniform interference fit shown in Fig. 1 with conventional geometry parameters and interference magnitude, the second die set was modelled with a uniform interference fit shown in Fig. 1 and optimized parameters, and the third one was modelled with a non-uniform interference and optimized parameters shown in Fig. 2. The contact pair definition in both the conventional structure and the proposed structure were shown in Figs. 1 and 2. All the contact pairs were defined as face-to-face. A contact face and a target face were defined in each contact pair. Element types of contact 170 and 174 were utilized to define the contact face and target face, respectively. The definition contact type is very important in the simulation. Compared with other contact types, the face-to-face contact pair has many advantages, such as supporting lower order and higher order elements, complex contact surface, smaller disk space, and CPU time requirement, etc. To reduce the calculating time, a single-tooth cavitydie model was constructed, and symmetrical boundary condition was employed (see Fig. 9).

\subsection{FEA results}

The path tool was employed to investigate the stress distribution. This tool can collect the output values of the variables (such as stress, strain and displacement) during the simulations at pre-defined points. For the outer ring, Path 1 was defined in the inner surface along the axial direction shown in Fig. 10, and the circumferential stress distribution on the path is shown in Fig. 11. Fig. 12 shows the Path 2 definition on the inner surface of the inner ring. Figs. 13 and 14 show the circumferential stress and radial stress along the path. Fig. 15 shows the Path 3 definition along the cavity die corner. The distributions of the first principle stress, von stress and strain along the path are shown in Figs.16, 17, and 18, respectively.

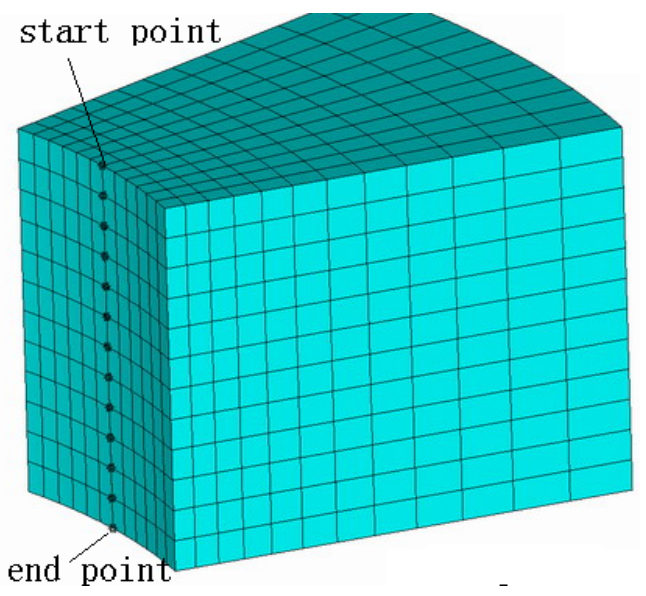

Figure 10. Definition of Path 1 at the outer ring.

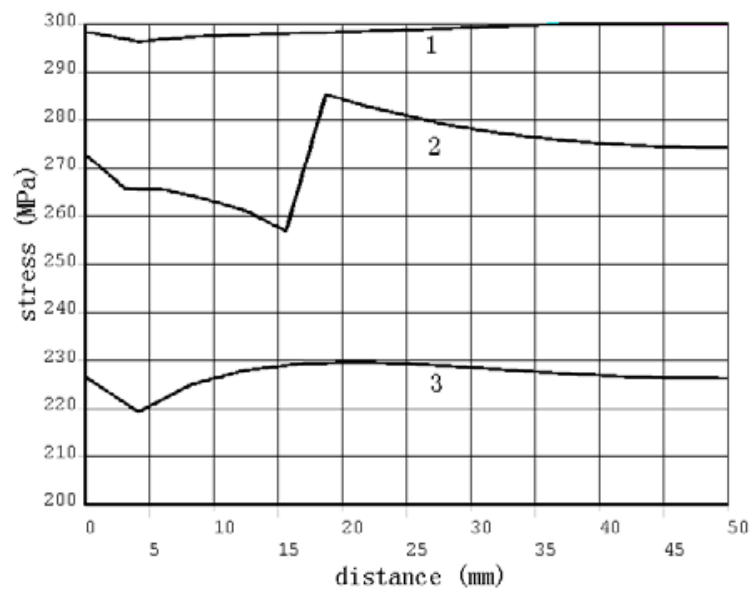

Figure 11. Stress distribution on Path 1 (1. first model; 2. second model; 3. third model). 


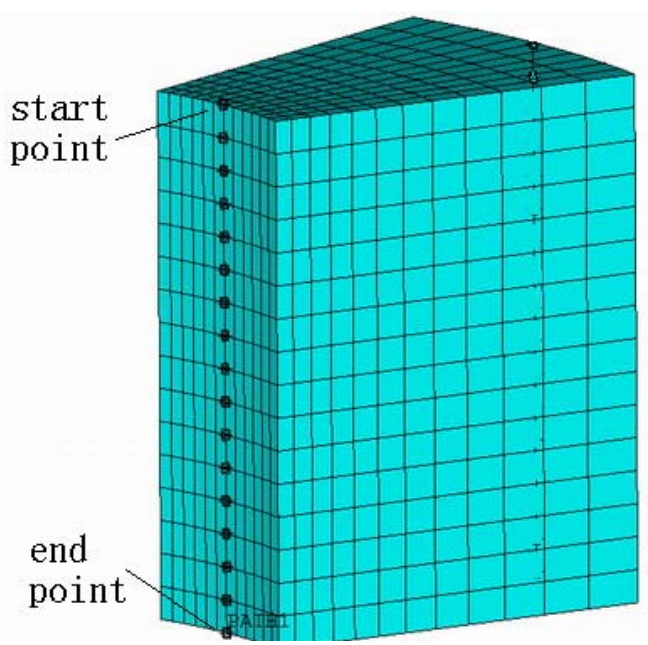

Figure 12. Definition of Path 2 at the inner ring.

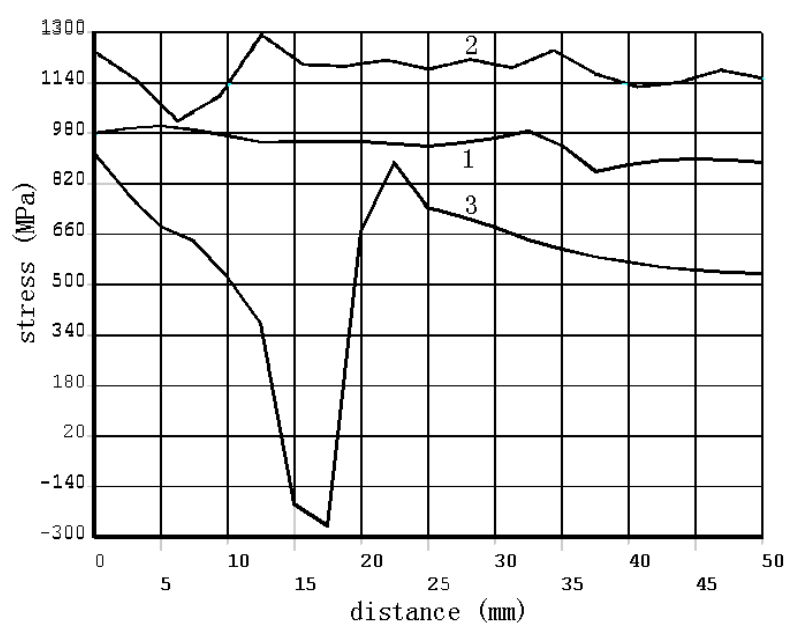

Figure 13. Circumferential-stress distribution on Path 2 (1. first model; 2. second model; 3. third model).

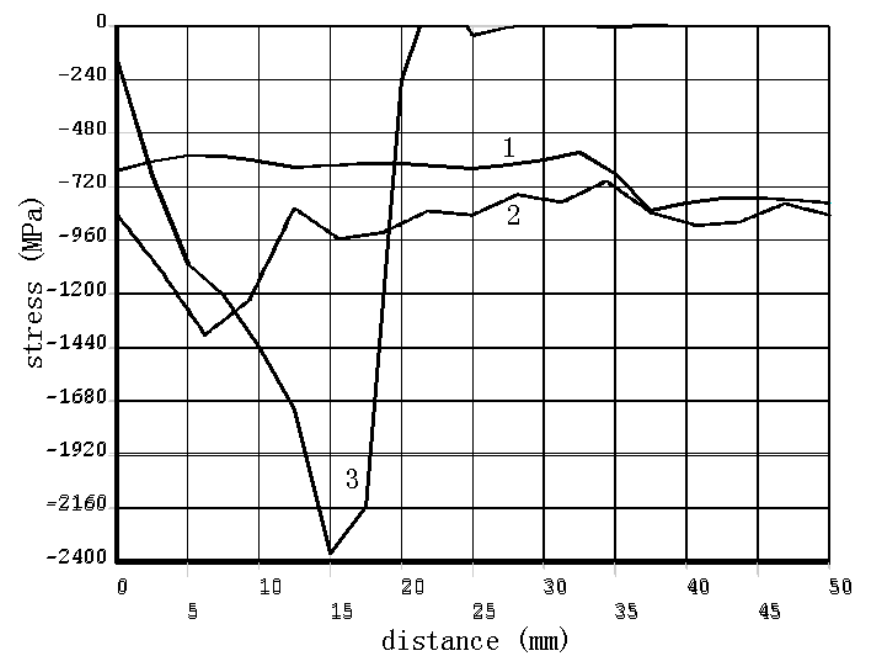

Figure 14. Radial-stress distribution on Path 2 (1. first model; 2. second model; 3. third model ).

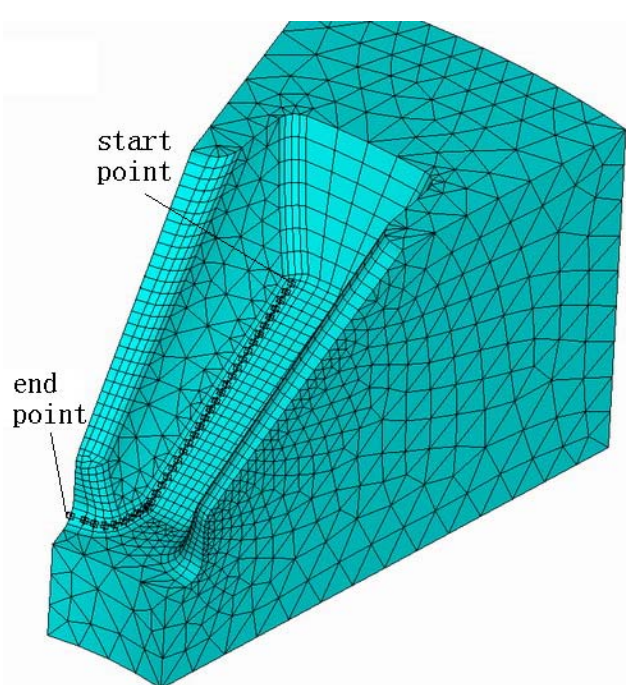

Figure 15. Definition of Path 3 at the cavity die.

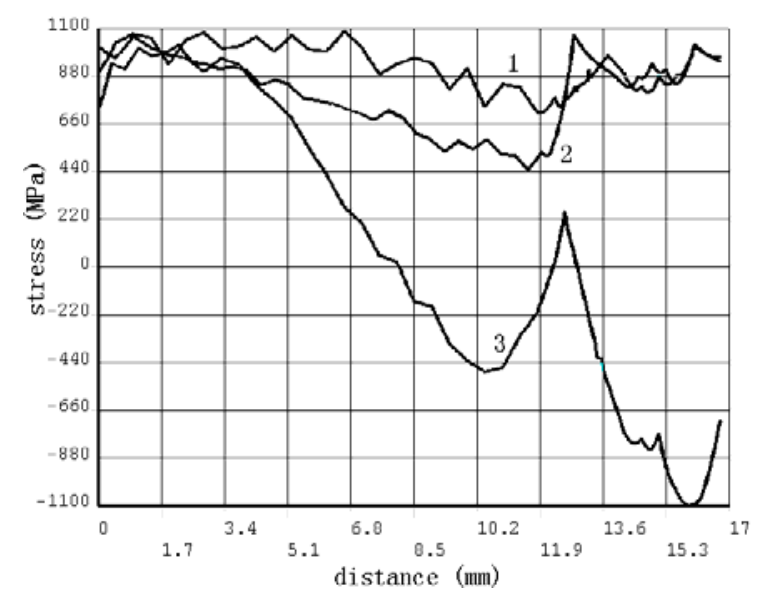

Figure 16. First principle stress distribution on Path 3 (1. first model; 2. second model; 3 . third model).

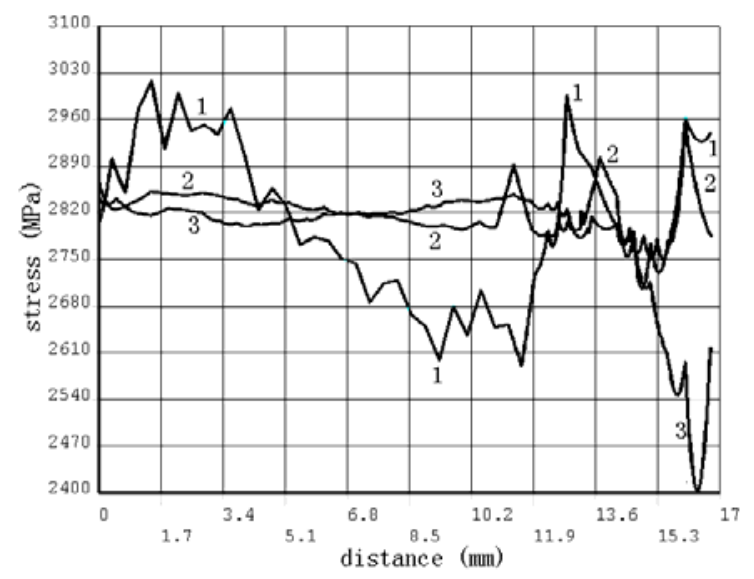

Figure 17. Von stress distribution on Path 3 (1. first model; 2. second model; 3. third model). 


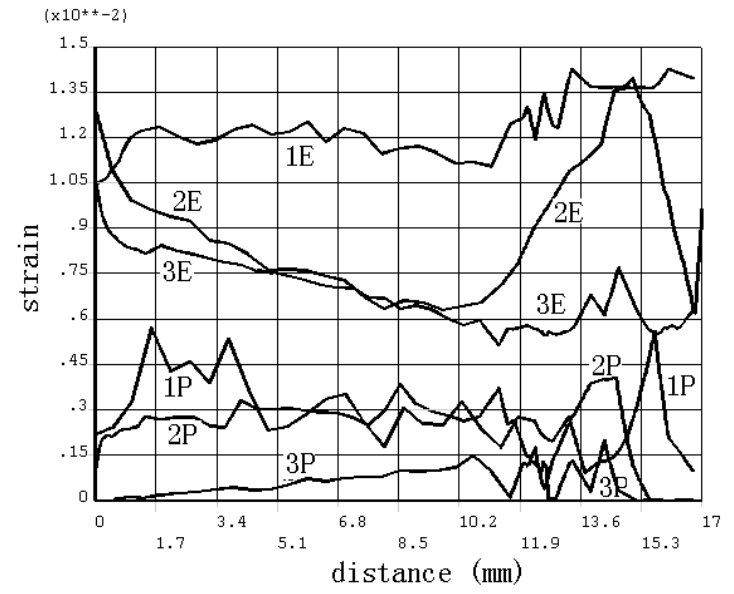

Figure 18. Strain distribution on Path 3 in three models (1E, 2E, 3E: elastic strain; 1P, 2P, 3P: plastic strain ).

\section{Experiment and application}

\subsection{Experiment conditions}

An involute bevel gear was chosen as the objective part, with its parameters shown in Table 4 and Fig. 19, respectively.

Table 4. Parameters of investigated bevel gear.

\begin{tabular}{|c|c|}
\hline Parameter & Value \\
\hline Number of teeth & 16 \\
\hline Module & $3.869 \mathrm{~mm}$ \\
\hline Pressure angle & $24^{\circ}$ \\
\hline Pitch diameter & $61.904 \mathrm{~mm}$ \\
\hline Pitch cone angle & $57.995^{\circ}$ \\
\hline Root cone angel & $50.734^{\circ}$ \\
\hline Tip angle & $63.317^{\circ}$ \\
\hline Tooth addendum & $2.850 \mathrm{~mm}$ \\
\hline Tooth dedendum & $4.640 \mathrm{~mm}$ \\
\hline Back sphere diameter & $76.850 \mathrm{~mm}$ \\
\hline Circular tooth thickness at big end & $5.693 \mathrm{~mm}$ \\
\hline
\end{tabular}

The gear material used in this research was $20 \mathrm{CrMo}$. It was annealed at $770{ }^{\circ} \mathrm{C}$ to a hardness of HB 140. The blank was a cylinder of $32 \mathrm{~mm}$ in diameter and $37 \mathrm{~mm}$ in height. Surface phosphate treatment was undertaken, and MoS2-oil mixture was used for better lubrication. $65 \mathrm{Nb}$ steel was employed for the cavity die. The die cavity was milled and polished to a roughness of $0.2 \mu \mathrm{m}$ after heat treatment to get a hardness of HRC 60.5. Forging was carried on a Y-28-400/400 double-action hydraulic press. A $3000 \mathrm{KN}$ clamping force $F$ was applied on dies based on previous experience.

\subsection{Die set}

According to the calculated results with MATLAB and FEA data with Ansys. Two types of die sets were designed, one was a three-layer assembled cavity die which was the same as the first FEA model, and the other was an assembled cavity die which was similar to the third FEA model. Die structure and corresponding die set are shown in Fig. 20.

\subsection{Experiments results}

The forged bevel gear was shown in Fig. 21. By using the die set of a uniform interference fit, a forming load $L$ of $3700 \mathrm{kN}$ was needed to fill the teeth cavities. Within 1000 forging cycles, the bottom corner of the second die set cracked (see Fig. 22). However, the bottom corner of the die set with non-uniform interference fit didn't crack until 10000 times of forging.

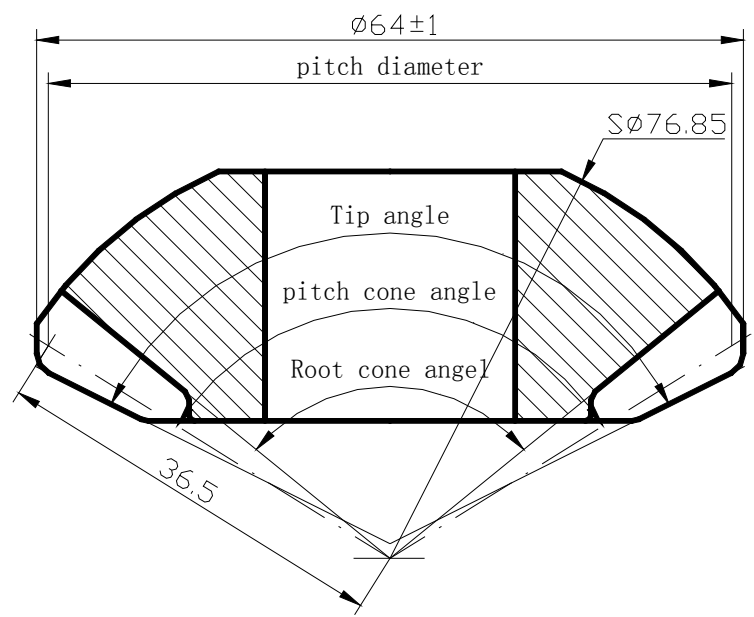

Figure 19. Parameters of the bevel gear. 

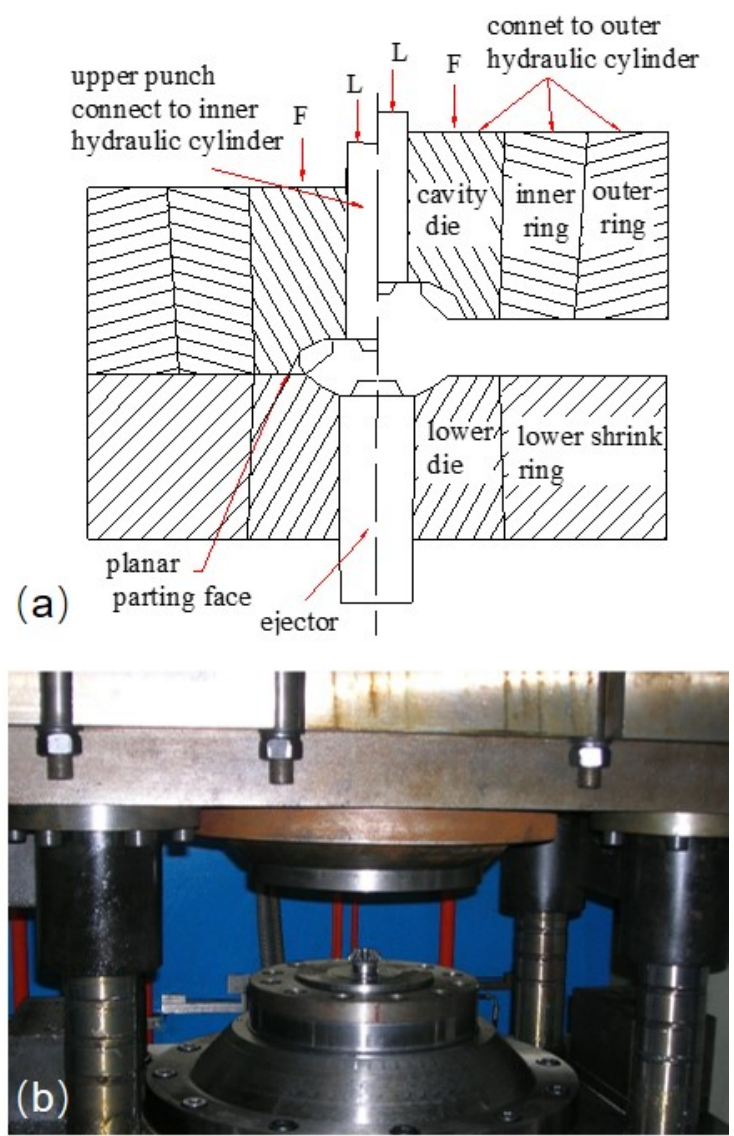

Figure 20. Illustration of the die structure (a) and experiment

die set (b).

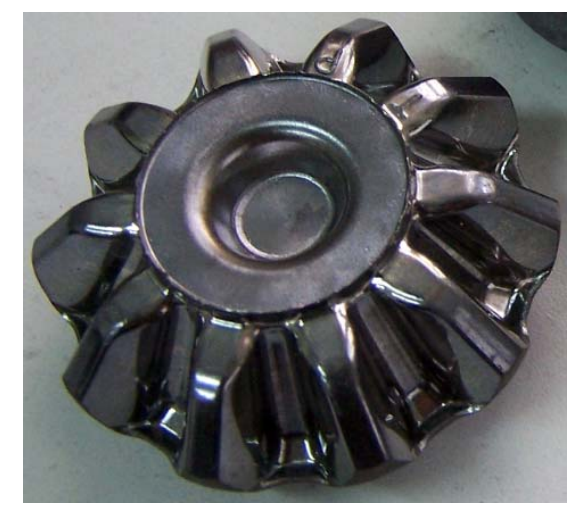

Figure 21. A forged bevel gear.

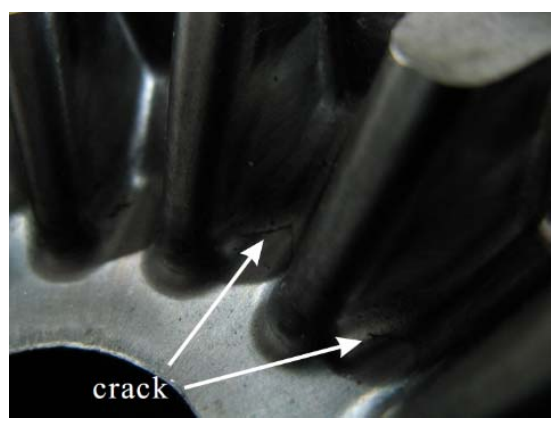

Figure 22. Failure of the die.

\section{Discussion}

Table 2 reveals that the two magnitudes of an interference fit between each layer are much different, the value of $\delta_{2}$ is $0.142 \mathrm{~mm}$ larger than that of $\delta_{3}$ in conventional design method. However, the two values are only $0.053 \mathrm{~mm}$ in difference with the optimized method. Table 3 reveals that $r_{2}$ and $r_{3}$ designed by the optimized method are 7.5 $\mathrm{mm}$ and $6 \mathrm{~mm}$, which are smaller than those by a the conventional method, respectively. The tangential tensile stress at the equivalent cylindrical face of the cavity die is reduced about $24.3 \%$, from $543 \mathrm{MPa}$ to $411 \mathrm{MPa}$.

Fig. 11 shows that the circumferential stress in the inner face of the out ring along Path 1 in the second model is lower than that in the first model. The corresponding stress in the third one is much lower than that in the former two. That means the outer ring of the third die is safer than the others.

According to Fig. 13, the second model has the highest circumferential stress along Path 2, and the third one has the lowest value. Especially, at a distance about $18 \mathrm{~mm}$, the circumferential stress in the third one changes from tensile state to compressive state. It indicates that the inner ring of the third die has the least risk of failure.

At the distance of $2 \mathrm{~mm}$ to $18 \mathrm{~mm}$ on the path, the third model has much bigger radial compressive stress, indicating the pre-stress applied on cavity die is safer (see Fig. 14).

The distributions of the first principle stress and von stress along Path 3 are shown in Figs. 16 and 17. From the distance of $8 \mathrm{~mm}$ to $17 \mathrm{~mm}$ on Path 3, the first principle stress becomes negative, which means the cavity die is in a purely compressive stress state (see Fig. 16). The maximum value of the von stress occurs in the first model according to Fig. 17. The higher von stress leads to the higher possibility of crack, and a cracked die designed in the first model is shown in Fig. 22.

No plastic deformation occurs in other place except at the corner on the Path 3 (see Fig. 15). According to Fig. 18 , the maximum plastic strain is $0.45 \%$ in the first model, $0.35 \%$ in the second model and only $0.2 \%$ in the third model. The plastic deformation distributes little to the whole model, so the model can be assumed to be elastic.

A little different can be found between the FEA results and the calculate values from MATLAB programming. The reason is that the shape of cavity die is not taken into consideration in MATLAB programming. However, they show the same variation tendency. Both the FEA and experiment results prove that the optimized die set with non-uniform interference fit is a better way to increase the service life of die with the non-uniform cavity and thick bottom. Mass production in Dongfeng Automobile Finished Gear Co. proves that the service life of die designed with the optimized method is over ten times longer than that of the die designed with the conventional method.

\section{Conclusions}

In this paper, a die structure with non-uniform interference fit was designed to improve the life of dies. 
The value of interference fit between the upper section and the inner ring was bigger than that between the lower section and the inner ring. The objective of optimization was to minimize the tensile stress by maximizing the prestress of shrink rings. A method that combined computer programming and thick-wall cylinder elastic solutions was employed to optimize the radius $r_{2}$ and $r_{3}$, and calculate the magnitudes of an interference fit. Based on the calculated results, FEA and experiments were conducted. Both FEA and experiment results proved that the structure of non-uniform interference fit can increase the service life of assembled cavity dies effectively.

\section{Acknowledgements}

We would like to express our deep gratitude to the National Key Technology Research \& Development Program of China (Grant No. 2006BAF04B06) and Hubei Provincial Technology Research \& Development Program Of China (Grant No. 2005AA101B19) for financial support and Dongfeng Finished Gear Plant for experiment support of this project.

\section{References}

[1] Kutuk M.A., Proceedings of the Institution of Mechanical Engineers, 217(2003)

[2] Fu M.W. and Shang B.Z., Journal of Materials Processing Technology, 53(1995)

[3] Song J. H. and Im Y. T., Journal of Materials Processing Technology, 192(2007)

[4] Zhang H. and Sun W., Forging \& Stamping Technology, 30(2005)

[5] Xu X.B., Metal Forming Technology, 21(2003)

[6] Lou H.W. and Gao, J.Z., Journal of Jiangsu Machine Building \& Automation, 1(2003)

[7] Luo Z.H. and Zhang Z.L., Journal of Plasticity Engineering, 36(2002)

[8] Zhang C.E., (Shandong University, Shandong, 2007)

[9] Xu B.Y. and Huang Y., Elastic-Plastic Mechanics and Application (Mechanical Industry Press, Peking, 1994)

[10]Li S.J., Datum for Forging Process and Die Design (Mechanical Industry Press, Beijing, 1991)

[11]Xia J.C., China Die \& Mould Design Canon (Jiangxi Science \& Technology Press, Jiangxi, 2003)

[12] Editorial Board of Operative Mould Technology, Mould Materials and Service Lives (Mechanical Industry, Beijing, 2004) 